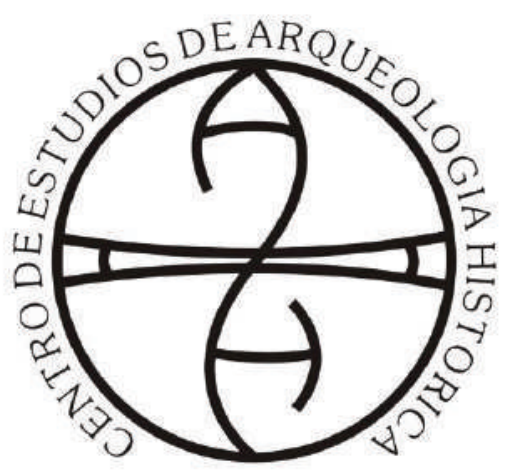

Centro de Estudios de Arqueología Histórica

Universidad Nacional de Rosario

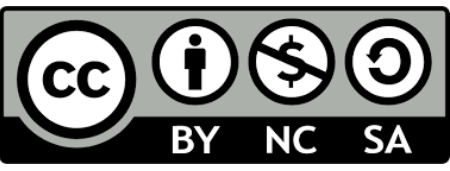

Teoría y Práctica de la Arqueología Histórica

Latinoamericana | Año IX, Volumen 11 | 2020

Revista del Centro de Estudios de Arqueología Histórica, Facultad de Humanidades y Artes,

Universidad Nacional de Rosario

https://teoriaypracticaah.unr.edu.ar/index.php/index

https://rephip.unr.edu.ar/handle/2133/14804

ISSN en línea: 2591-2801

ISSN versión impresa: 2250-866X

Atribución-NoComercial-CompartirIgual 4.0 Internacional (CC BY-NC-SA 4.0)

https://creativecommons.org/licenses/by-nc-sa/4.0/deed.es

Nélida De Grandis. Indicios sobre actividad textil en San

Bartolomé de los Chanás. Reducción franciscana del siglo

XVII. Monje. Provincia de Santa Fe

\title{
INDICIOS SOBRE ACTIVIDAD TEXTIL EN SAN BARTOLOMÉ DE LOS Chanás. Reducción franciscana del siglo XVII. Monje. Provincia de Santa Fe
}

\section{Evidence on teXtile activity in SAn Bartolomé de los Chanás. Franciscan REDUCTION OF THE 17TH CENTURY Monje. Province of Santa Fe}

\author{
Nélida De Grandis*
}

\section{Resumen}

En este trabajo se estudia un conjunto de torteros que pudieron estar asociados a la actividad textil realizada en ese ámbito reduccional y de encomienda para abastecer las necesidades de la vida cotidiana de sus pobladores. Se sabe que en este contexto, las mujeres indígenas desempeñaron un rol muy importante como hilanderas y tejedoras dedicadas especialmente a la fabricación de lienzo para uso doméstico y el excedente se colocaba en el circuito comercial local y regional, cuyo centro era Santa Fe la Vieja. Se investiga además, la relación tamaño y peso de esos artefactos para hallar datos sobre las posibles fibras que se pudieron haber empleado.

Palabras clave: Indígenas Chaná y Guaraníes, Reducción, Franciscanos, Actividad textil

\section{Abstract}

This work studies a set of bulls that could be associated with the textile activity carried out in this area

Centro de Estudios de Arqueología Histórica. Facultad de Humanidades y Artes. Universidad Nacional de Rosario. E-Mail: nellyisis@hotmail.com 
of reduction and entrust to meet the needs of the daily life of its inhabitants. It is known that in this context indigenous women played a very important role as spinners and weavers dedicated especially to the manufacture of canvas for domestic use and the surplus was placed in the local and regional commercial circuit, whose center was Santa Fe la Vieja. Further research is conducted on the size and weigth ratio of these artifacts to find data on possible fibres that may be used.

Keywords: Indigenous Chaná and Guaraníes, Reduction, Franciscans, Textile activity

\section{Introducción}

El objetivo de este trabajo es dar a conocer evidencias sobre la actividad textil donde tuvo su asiento la reducción San Bartolomé de los Chaná a cargo de un religioso de la Orden Franciscana creada en el año 1617 en la localidad de Monje, Provincia de Santa Fe.

Dentro de las prospecciones y excavaciones que se realizaron en ese sitio denominado La Boca, espacio que ahora ocupa el Balneario Municipal, se recuperaron objetos propios de la vida cotidiana de sus habitantes. En esta oportunidad estudiamos una colección de 15 torteros (contrapeso del huso de hilar), elementos indispensables para lograr hilos con diferentes tipos de fibras usadas para producir tejidos.

La fundación de Santa Fe la Vieja (SFLV) en 1573 por Juan de Garay marca el comienzo de la conquista y colonización del espacio santafesino. En la nueva ciudad los primeros pobladores ocuparon, según su jerarquía social, espacios privilegiados cercanos a la Plaza Mayor. Hacia la periferia de ejido urbano, sobre el albardón costero, se repartieron lotes para la instalación de chacras o "tierras de pan llevar" dedicadas al cultivo de trigo, maíz, algodón y ganado lanar. Más alejadas y en tierras menos fértiles se ubicaron las estancias, espacios para la cría de ganado bovino y mular, motor importante de la economía de SFLV, en las que trabajaban indígenas encomendados y africanos esclavizados. Ambos emprendimientos funcionaron como unidades económicas productoras de bienes comerciales.

De esta manera el espacio santafesino será compartido por grupos originarios, indígenas guaraníes llegados desde Asunción, europeos, criollos y africanos esclavizados provenientes de Angola y Guinea dando lugar a diferentes y complejos procesos sociales.

En los primeros años de Santa Fe la Vieja no había circulante metálico por lo que las transacciones comerciales se realizaban mediante trueque y los valores estaban relacionados con productos de la tierra. A partir del año 1575 el lienzo se usó como unidad monetaria. Parte de su producción fue utilizada para cubrir las necesidades de la sociedad santafesina y el resto ingresaba al mercado comercial interno a través de los mercaderes.

\section{Expansión y consolidación de las nuevas tierras}

La etapa de expansión hacia el sur de Asunción se inició con el plan político de Juan de Garay de abrir puertas a la tierra con el objetivo de lograr una salida al mar para favorecer las relaciones con España y desplegar un dispositivo de seguridad en la consolidación del territorio a lo largo del corredor paranaense. La fundación de los primeros centros urbanos se realizó entre los años 1573/1588: Santa Fe 1573, Buenos Aires 1580, Concepción del Bermejo 1585 y Corrientes 1588. Sirvieron para sostener la colonización dedicada a la cría de ganado bovino y mular, a la producción de trigo y maíz además de funcionar como puestos de abastecimiento de las rutas comerciales y contribuir a la pacificación de la tierra. 
Esta ocupación se afianzó por un lado con el otorgamiento de encomiendas a los vecinos feudatarios; quienes en Santa Fe estarán vinculados al gobierno, comercio, vaquerías y por otro, con la instalación de reducciones.

Fue Hernando Arias de Saavedra (Hernandarias) criollo -nacido en Asunción e hijo de españolesquien completó el plan de conquista y colonización en sus gestiones como Gobernador con la incorporación de mayores superficies de tierras productivas y el establecimiento de grupos indígenas en reducciones. Para esta tarea convocó a misioneros franciscanos, Orden por la que sentía notable preferencia tal como lo expresa en su Carta al Rey del 28 de julio de 1616:

[...] yassi solo los de san francisco son los que requiere esta prouincia Por ser pobres , y sustentarse con facilidad por que los demas (refiriéndose a otras Ordenes) atienden a sus comodidades, de fundar colegios y haciendas con que sustentarse Por lo cual los indios no tienen aficion a otros que los franciscanos. (Revista de la Biblioteca Nacional TI.,1937:386).

Con estas reducciones ubicadas a lo largo del río Paraná trató de consolidar y liberar esta importante vía de comunicación entre Asunción- Buenos Aires y España. Entre los años 1615 y 1616 colaboró, incluso con ayuda económica personal, en el asiento de seis centros reduccionales ubicados en sitios costeros a fin de concentrar a la población indígena para que adquirieran hábitos civilizados y fueran centros de propagación de la fe católica. En su Carta al Rey del 25 de mayo de 1616 escribe:

[...] en las reduciones Referidas donde ay sacerdotes tengo rrepartidas quarenta campanas del tamaño necesario a mi costa como los otros gastos precisos para regalar y acariciar estos naturales pues las dadibas los amansan como a barbaros para atraerlos y que Reciuan la ley euangelica. (Revista de la Biblioteca Nacional TI, 1937: 386).

Estos asientos fueron: Provincia de Buenos Aires: Santiago de Tubichaminí; Provincia de Santa Fe: San Lorenzo de los Mocoretás, San Miguel de los Calchines y San Bartolomé de los Chanáy en Provincia de Corrientes: Nuestra Señora de la Limpia Concepción de Itatí y Santa Lucía de los Astor o Astores. Hacia la misma época fueron creadas en Provincia de Buenos Aires otras dos reducciones como Santiago del Baradero por gestión de fray Luis de Bolaños en 1615 (Figura 1). 


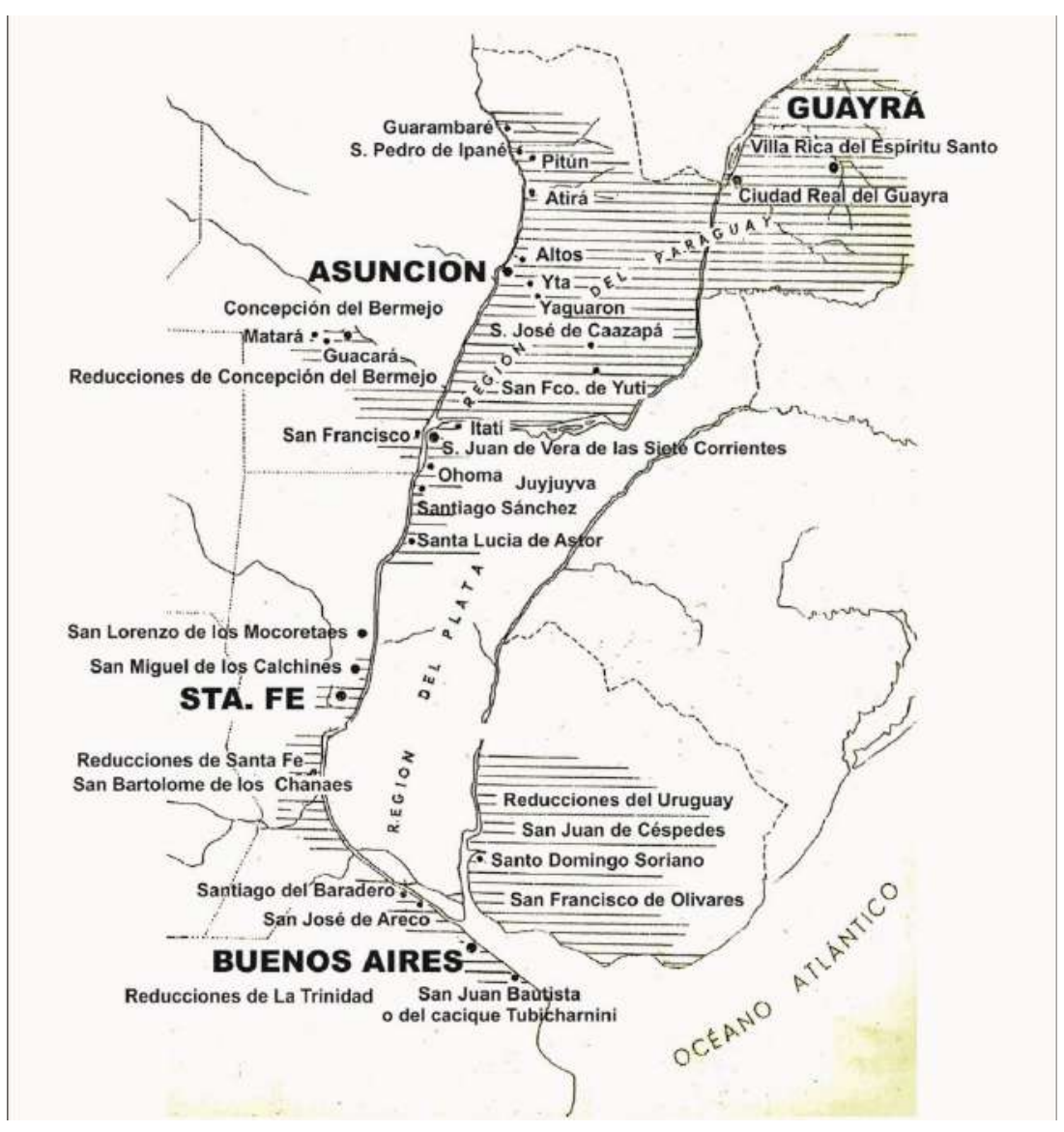

Figura 1. Mapa ubicación de las reducciones (Molina, 1948)

\section{La Boca}

Este sitio que tiene documentación histórica asociada, está ubicado en la confluencia del arroyo Monje con el río Coronda, un afluente del Paraná Inferior en la costa de la pampa elevada santafesina con clara orientación fluvial (Figura 2).

En La Boca, como se lo reconoce actualmente al sitio, la distribución arqueológica presenta una combinación de materiales indígenas locales (Goya- Malabrigo) guaraníes y elementos europeos que nos permitirá ir conociendo los procesos socioculturales que se pudieron haber dado en el ámbito reduccional.

\section{Historia del sitio}

Está situado sobre tierra firme en la confluencia del río Coronda y el arroyo Monje. Se accede por camino de tierra y está distante de la localidad de Monje, de la cual depende, a unos 10km hacia el NE (Figura 3). 


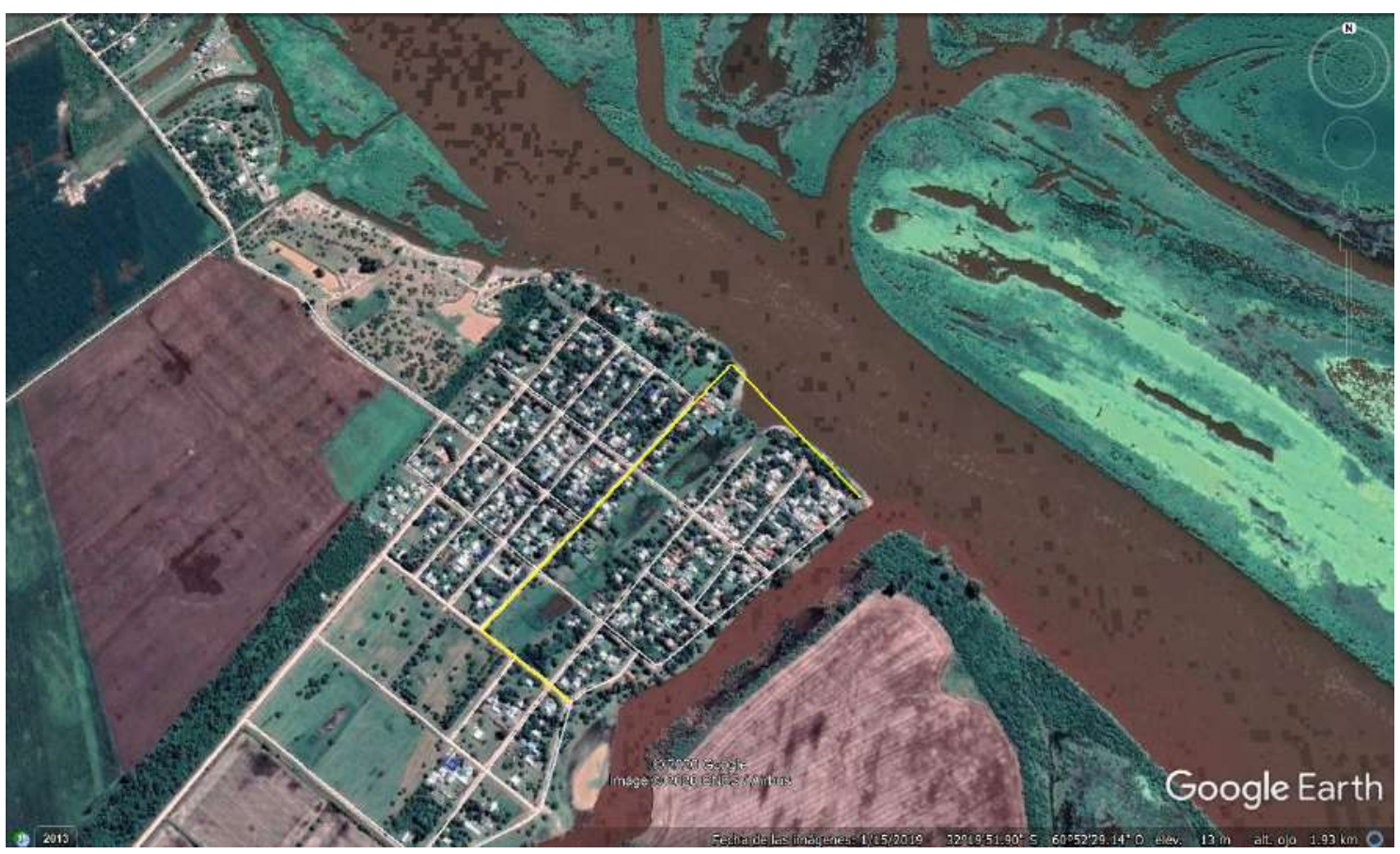

Figura 2. Ubicación del Balneario La Boca. Monje. Provincia de Santa Fe

En este sitio desde hace aproximadamente unos 50 años se practican actividades de pesca y en menor escala, caza de aves (patos) y fauna terrestre (nutria, carpincho) razón por la cual los fines de semana colma su capacidad para recibir turistas locales y de provincias limítrofes. El predio fue loteado, parcialmente deforestado y se construyeron viviendas para una población permanente (alrededor de 20 familias) y casas de fin de semana.

En la faja costera del arroyo Monje se ubican las carpas y en el sector frente al río Coronda están emplazados los fogones y mesas móviles. Cuenta con servicios de almacén, instalaciones sanitarias, funciona un dispensario, una escuela primaria y una pequeña capilla (Figura 4).

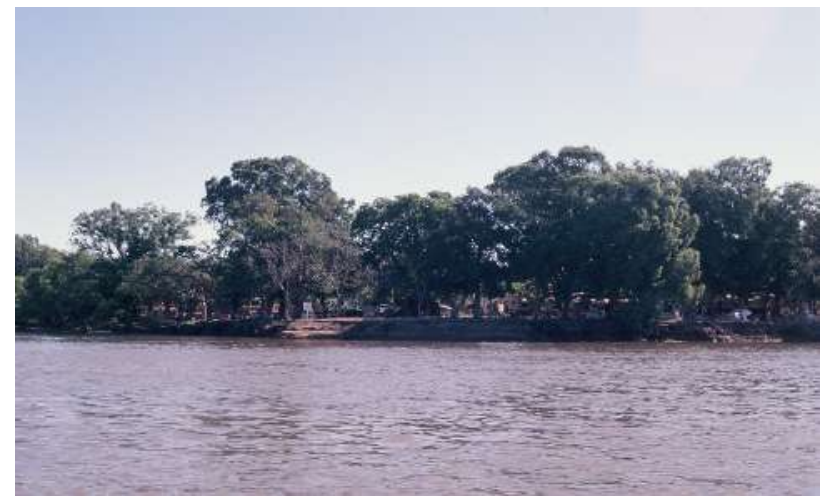

Figura 3. Vista del sitio desde el Río Coronda, Monje. Provincia de Santa Fe 

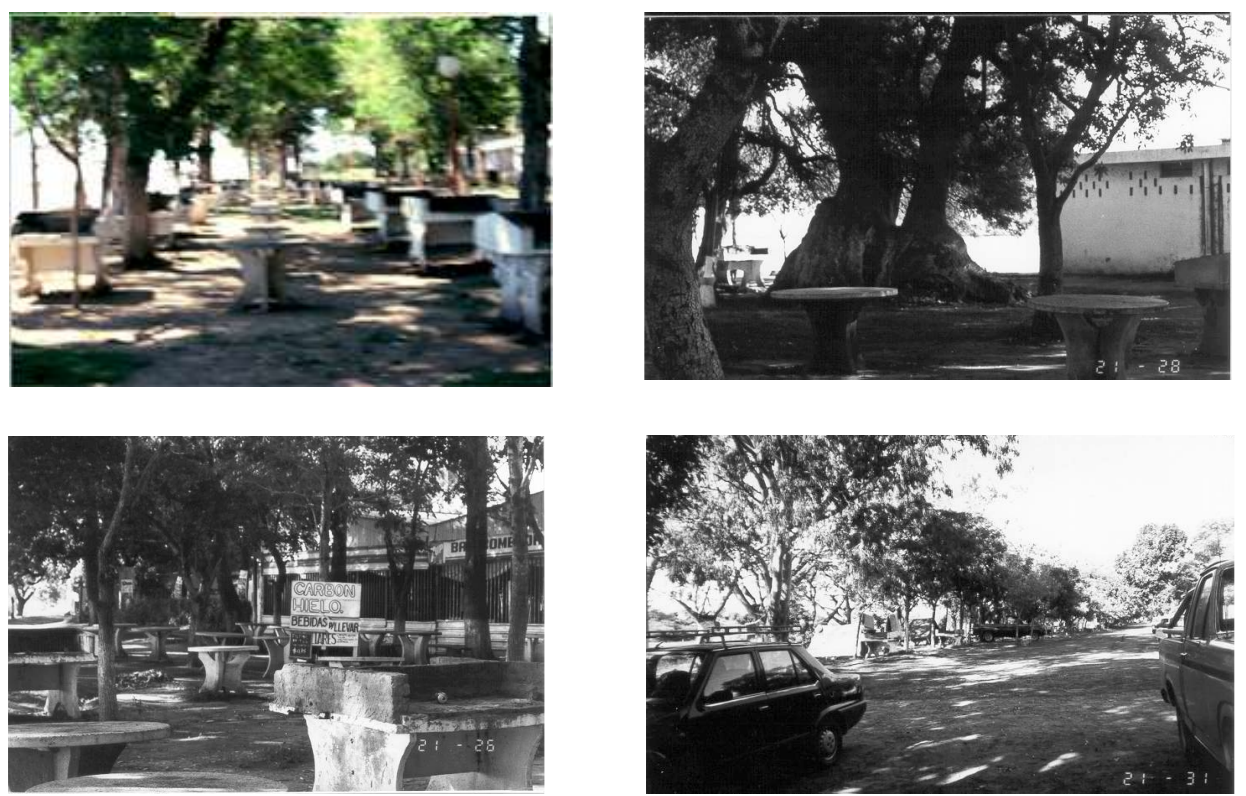

Figura 4. Vista del balneario La Boca. Monje. Provincia de Santa Fe

La reducción de San Bartolomé de los Chaná estuvo asentada en este lugar. Creada hacia 1616 por Hernandarias perteneció a la encomienda de Pero Gómez, vecino encomendero de Santa Fe y que luego hereda su hijo Luis por segunda vida.

Cuando el Gobernador Diego de Góngora realiza una visita a todas las reducciones de la Gobernación del Río de la Plata en 1622, la encuentra casi despoblada porque sus habitantes habían sufrido una epidemia de viruela y sarampión. De la población original 321 personas, en esa oportunidad se empadronaron sólo 50 indígenas integrantes de dos grupos étnicos: chanáy guaraníes. A pedido del Gobernador se vuelve a repoblar y hacia 1646 queda casi abandonada.

En el año 1650 reclama sus derechos Diego Tomás de Santuchos y en su pedimento consigna que hay sólo 6 indios de tasa. En el año 1682 hay un nuevo llamado a Edictos y se presenta Juan de Aguilera, a quien el gobernador José de Garro se la adjudica tomando posesión el 28 de marzo de 1683 (Cervera, 1982).

Las últimas noticias que se tienen de esta reducción son las que aporta el Padre Pedro Lozano en su libro "Historia de la conquista del Paraguay" (1874: 139) donde dice:“[...] tal cual paredón que señala su antiguo sitio sin permanecer indio alguno."

Este sitio arqueológico nos plantea el problema de cómo abordar la información arqueológica cuando ésta corresponde a la etapa de colonización europea en estos territorios y cómo describir e interpretar la materialidad arqueológica en un sistema económico globalizado -que aporta nuevas ideas y tecnologías- y con la presencia de etnias con diferentes estadios de desarrollo cultural.

Dentro de los materiales que fueron recuperados un grupo de torteros, elementos vinculados a la producción textil, suponemos, fue realizada por las mujeres que vivieron en esa reducción. 


\section{Producción textil}

Dentro de la cultura material recuperada se obtuvieron 15ejemplares de torteros, (entendiendo para este caso, que es el contrapeso del huso de hilar, disco redondo de arcilla o loza). Cuatro ejemplares fueron realizados en forma intencional; ocho, a partir de vajilla doméstica descartada de tradición indígena-local o guaraní- y tres fragmentos reciclados de lozas importadas de procedencia europea como Talavera, Ichtuknee y americana, Panamá Polícromo, (Schávelzon, 1998) hallándose ejemplares similares en la ciudad de Santa Fe la Vieja.

Respecto a la presencia de fragmentos reciclados de lozas europea y americana en esta reducción sugiere la posibilidad que hayan sido vajillas utilizadas por el fraile franciscano que estuvo a cargo de la reducción, o haber sido traídas por el encomendero Pedro Gómez, y que al romperse, fueran descartadas, Posteriormente, quizás esos fragmentos son los que se pudieron haber reutilizado para fabricar los torteros. Por otra parte, suponemos que la perforación de ellos, se pudo haber realizado con una punta metálica (clavo de hierro?) dada la dureza de la superficie a atravesar.

Lo importante es que estos hallazgos podrían estar vinculados, en principio, a los envíos de loza europea que hacían tanto la Corona española como las Órdenes religiosas hacia diferentes puertos americanos para abastecer la creciente demanda de este producto.

Respecto a la loza americana, fabricada en Panamá, (Panamá Polícromo 1600/1650), pudo haber llegado a través de redes comerciales que estaban activas, para esa época, en el sur del continente americano, Lima, Chile o por el Océano Atlántico, el puerto de Buenos Aires.

\section{Tejidos y Telas}

Los tejidos más comunes de la época fueron el lienzo de diferentes calidades como el "sayal", el más burdo, el lienzo delgado y la combinación de hilado de algodón y lana.

\section{Fibras}

Para la obtención de las fibras el principal instrumento utilizado en esa época fue el huso de mano, compuesto por una varilla rígida de madera con un peso (tortero) el cual tiene un orificio centrado para mantener su equilibrio y permitir la obtención de la fibra ordenada. El diámetro, espesor y peso de un tortero son factores esenciales para el rendimiento del mismo y está en relación con el grosor del hilo producido.

Los torteros de mayor diámetro y peso son ideales para lograr un hilado medio a grueso; los más pequeños son utilizados para lograr hilos más finos para confección y/o reparación de prendas, por ejemplo.

¿Qué tipos de fibras se pudieron haber utilizado en esta Reducción?

La producción textil parece haber tenido un carácter doméstico. El hilado y tejido se pudo haber realizado en las viviendas y suponemos que se optimizaron el uso de la lana de oveja proveniente de las chacras y estancias santafesinas. El algodón pudo obtenerse localmente ya que se cultivaba en pequeña escala en las chacras santafesinas, pero también se traía de Corrientes. Respecto a la variedad, se supone que la especie fue Gossypiumhirsutum. Su probable centro de origen fue América Central, región donde se encontró la máxima diversidad de tipos y hábitos de crecimiento (Arturi,1984).

La fibra de algodón debe reunir determinadas propiedades que están relacionadas con su rendi- 
miento. Ellas son: 1) el color: que depende de la variedad; 2) longitud de la fibra: de ella depende la resistencia del hilado y su apariencia, ya que los algodones de fibras cortas se utilizan para fabricar hilados de menor calidad, en tanto que los de mayor longitud se los aplica para tejedurías finas; 3) resistencia: al momento de la cosecha y según la madurez que tenga el fruto se obtendrá fibras más resistentes como por ejemplo, para hilos de coser; 4) homogeneidad: esta característica se logra cuando las fibras son similares ya sea en longitud, grosor y resistencia; 5) limpieza: el algodón presenta impurezas como hojas secas, fragmentos de semillas, tierra, etc, que si no se eliminan con el desmotado, aparecen en el tejido alterando la uniformidad de la tela y en el proceso de teñido absorben los colorantes en forma diferencial. (Arturi, 1984).

Respecto a la fibra animal- en este caso lana de oveja- el tratamiento comenzaba, luego de la esquila con el lavado, secado y cardado para quitarle las impurezas. Luego se pasaba a la fase de hilado tarea que realizaban las mujeres empleando el huso de mano.

\section{Hilado}

Se realizaba trabajando con el huso a fin de lograr hebras de similar longitud y grosor. Como para hilar el algodón es necesario que las fibras tengan cierto grado de humedad a fin de lograr su flexibilidad, el sebo pudo haber sido un elemento incorporado por las hilanderas para facilitar el manejo de las fibras.

\section{Torsión}

Es la técnica por la cual se arrollan los hilos en forma helicoidal y se realiza para lograr elasticidad y darle resistencia al hilado.

\section{Estudio de la Colección}

Las categorías utilizadas en este trabajo a fin de facilitar información detallada, fueron: manufactura, materia prima, estado de la pieza, pasta, tratamiento de superficie, perfil, diámetro máximo, diámetro del orificio, espesor y peso (Figuras 5 a 8).

\section{Tabla 1: Primera aproximación al análisis de los materiales}

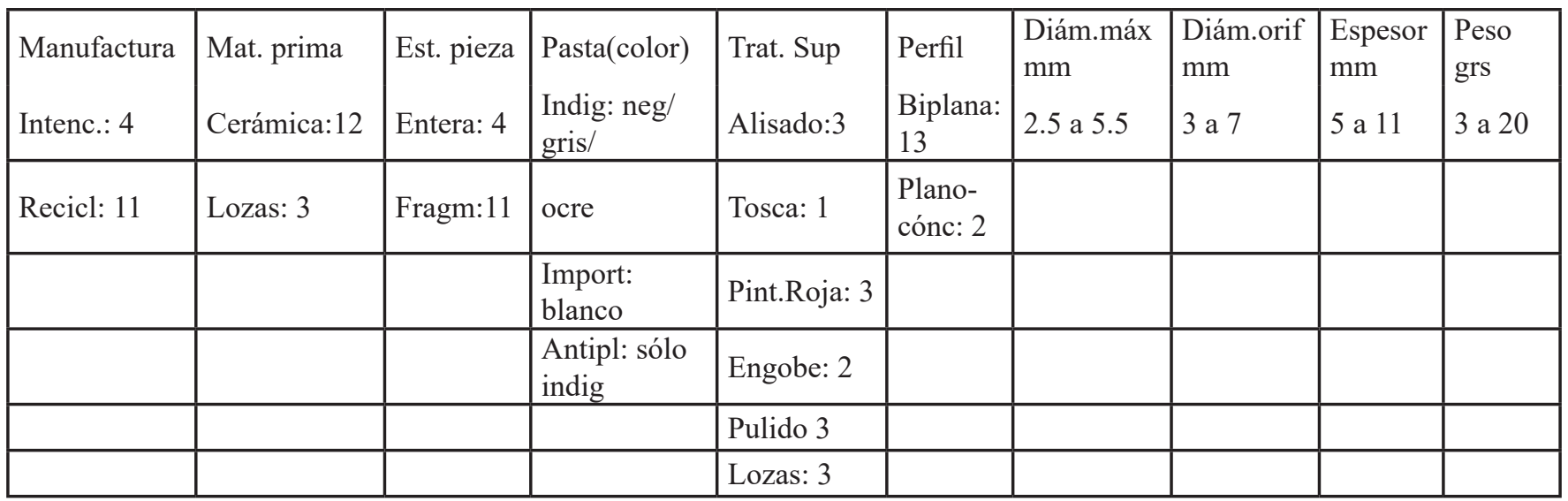

Tabla 1: Las categorías elegidas permitieron obtener información específica de las piezas estudiadas. 

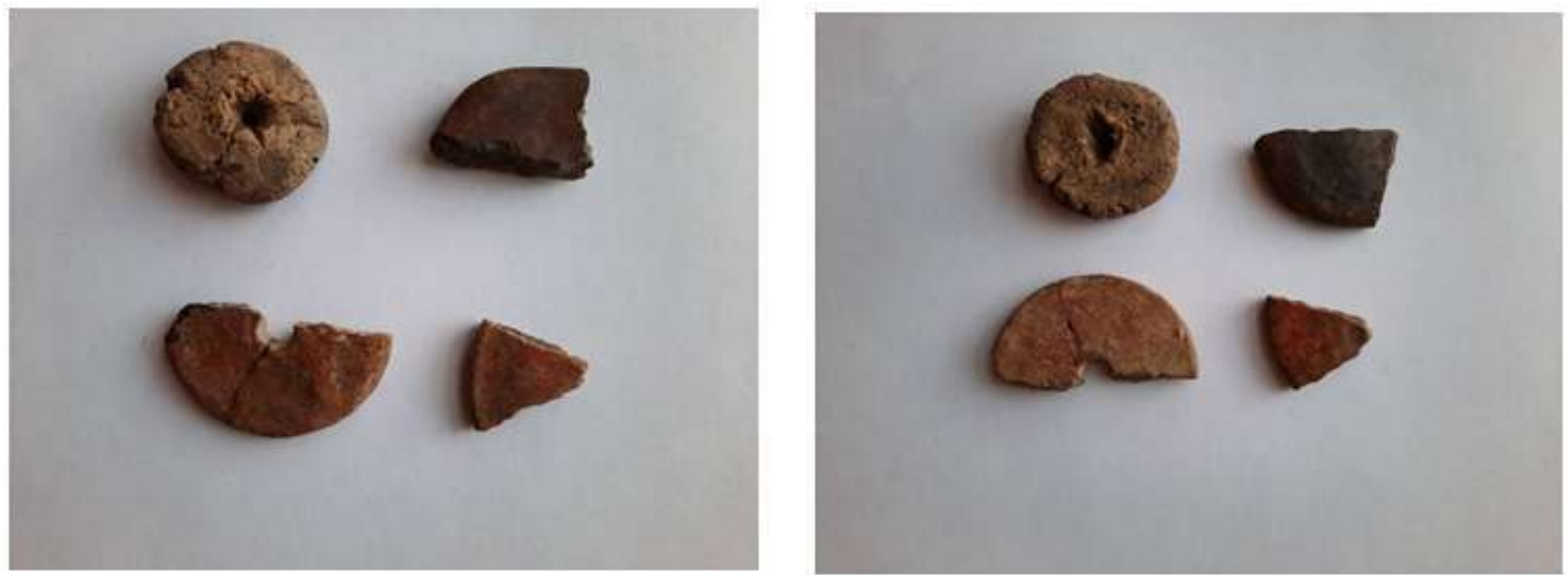

Figura 5. Anverso y reverso. Torteros hechos intencionalmente con pasta y color en cerámica indigena. Uno entero y tres fragmentados.
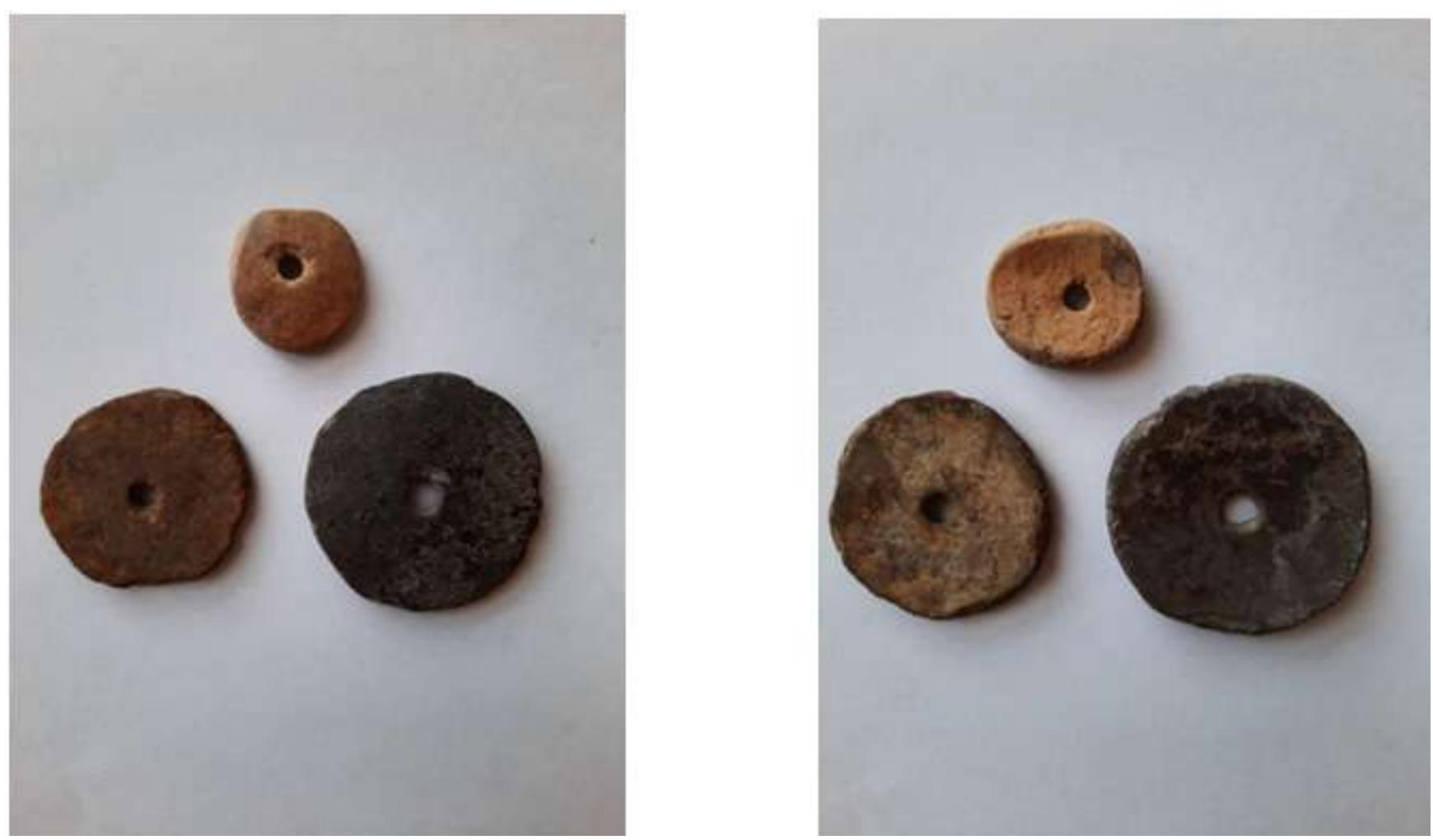

Figura 6. Anverso y reverso. Torteros enteros realizados a partir de fragmentos reutilizados de cerámicas indigenas. 

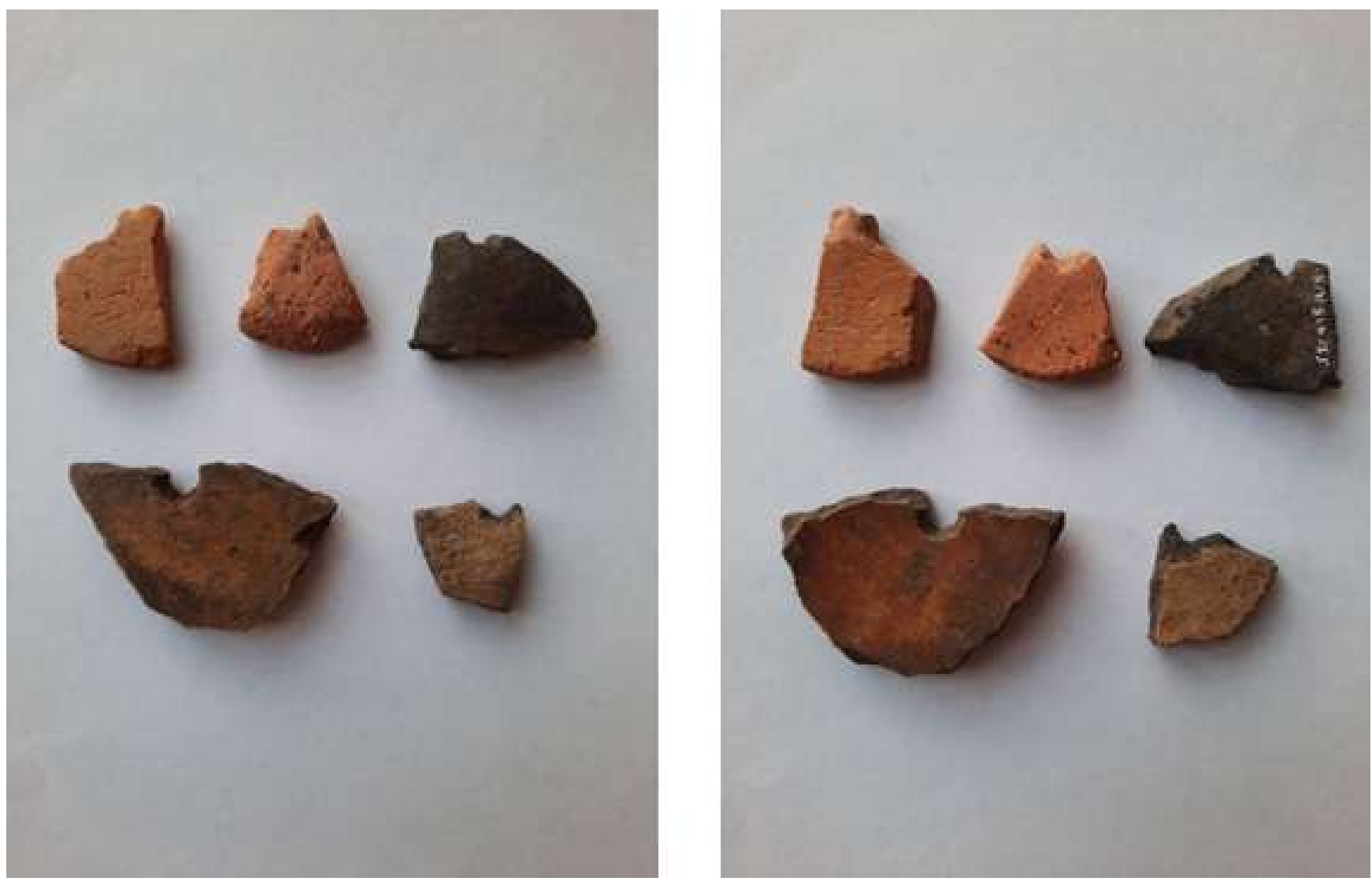

Figura 7. Anverso y reverso. Torteros fragmentados realizados a partir de la reutilizaciónde de cerámicas indígenas.
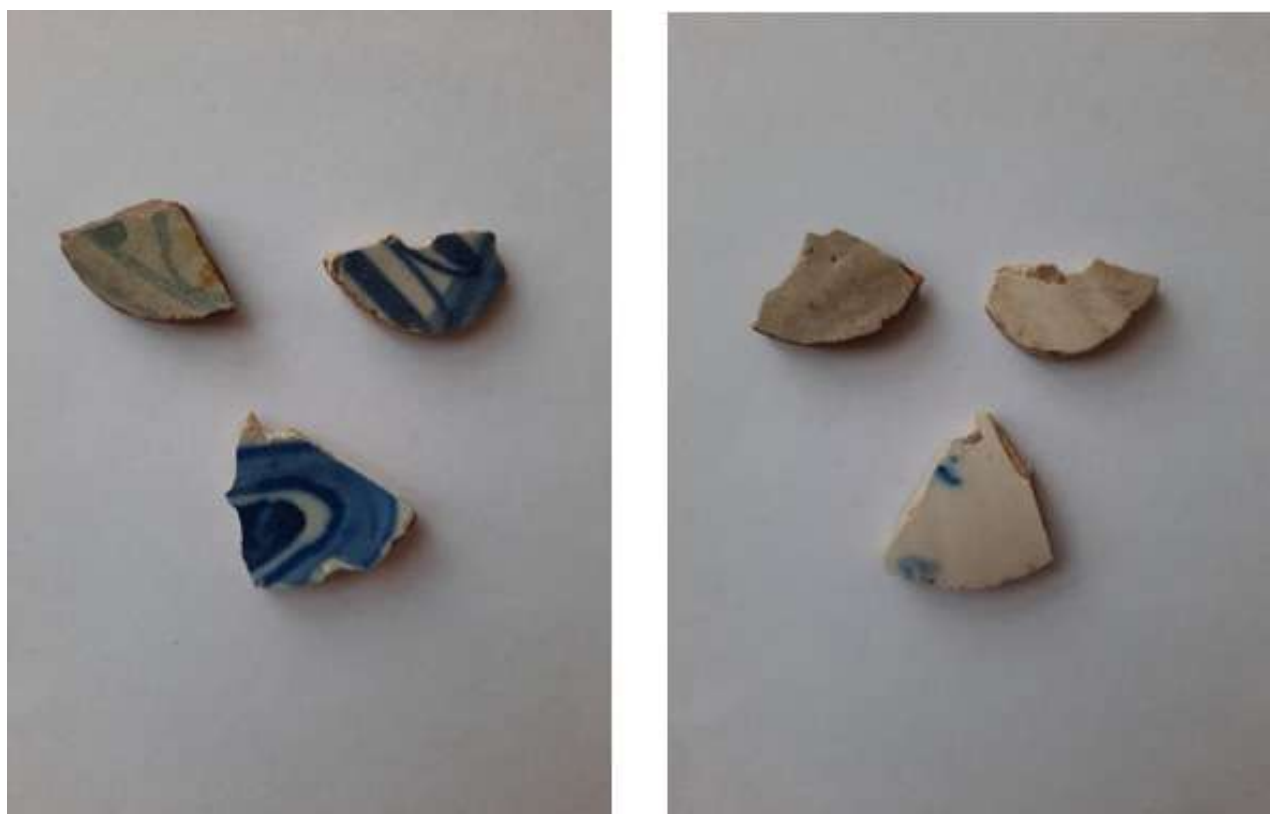

Figura 8. Anverso y reverso. Torteros confeccionados a partir de fragmentos reutilizados de lozas europeas: Talavera, Ichtuknee y americana Panamá polícromo. 
Teoría y Práctica de la Arqueología Histórica Latinoamericana

Año IX, Volumen 11 | 2020 / ISSN en línea: 2591-2801 | ISSN versión impresa: 2250-866X

Tabla 2: Descripción detallada sobre las características de cada ejemplar

\begin{tabular}{|c|c|c|c|c|c|c|c|c|c|}
\hline \multirow{2}{*}{\begin{tabular}{|l}
$N^{\circ}$ \\
pieza \\
\end{tabular}} & \multirow{2}{*}{ Proced, } & \multirow[t]{2}{*}{ Adscrip.cult } & \multirow[t]{2}{*}{ Mat prima } & \multicolumn{3}{|c|}{ Dimensión en mm } & \multirow{2}{*}{\begin{tabular}{|l} 
Peso \\
en grs.
\end{tabular}} & \multirow{2}{*}{ Morfol } & \multirow[t]{2}{*}{ Descripción de materiales } \\
\hline & & & & dia.tot & diá orif & lespes. & & & \\
\hline 1 & donación & indigena & cerám & 4 & 4 & 11 & 17 & biplana & Intencional. Pieza entera. De factura irregular, tosca, con estrías en ambos lados por \\
\hline & & & & & & & & & aplastamiento que produjeron estrías en ambas caras. Pasta color ocre. Donación Sr.Coquin. \\
\hline 2 & Rec.sup & indigena & cerám & 5,4 & 7 & $5 / 7$ & 11 & biplana & Intencional. Fragm por la mitad Ambas sup con P/R. La parte sup.pulida y la inferior alisada \\
\hline & & & & & & & & & Pasta con abundantes tiestos molidos. Cocción reductora. \\
\hline 3 & C S 48 & indigena & cerám & 3,7 & 5 & 7 & 9 & biplana & Intencional. $1 / 4$ de fragmento. Parte sup. pulida con engobe rojo diluido; reverso alisada con \\
\hline & W12/zar & & & & & & & & con pintura roja. Orificio realizado desde la parte sup. Pasta cocc. reductora con tiestos molidos. \\
\hline 4 & C1 Niv 1 & indigena & cerám & 2,6 & 4 & 7 & 5 & biplana & Intencional. $1 / 4$ de fraginento. Parte sup alisada con engobe color marrón/rojizo pulido y \\
\hline & & & & & & & & & ocre claro sobre el borde.Pasta de color negro. \\
\hline 5 & Rec.sup & indigena & cerám & 3,2 & 5 & 7 & 8 & plano/ & Entera. Reutilización frag.ceramico. Superficie ext/int alisada. Pintura roja desleida. Pasta \\
\hline & & & & & & & & concav. & oxidante. \\
\hline 6 & Rec.sup. & indigena & cerám & 5,5 & 6 & 6 & 20 & biplana & Entera. Reutilización frag cerámico. Sup.externa restos hollin. Sup.int alisada con restos hollín. \\
\hline & & & & & & & & & Pasta con tiestos molidos. \\
\hline 7 & Rec sup & indigena & cerám & 4,6 & 5 & 5 & 16 & plano/ & Entera. Reutilización frag cerámico. Superficie int/extema alisada Pasta oxidante. \\
\hline & & & & & & & & concav. & \\
\hline 8 & Rec.sup & indigena & cerám & 3,2 & 4 & 6 & 5 & biplana & 1/4 de la pieza. Reutilización frag cerám. Cocción oxidante. El orificio central está levemente \\
\hline & & & & & & & & & marcado. \\
\hline 9 & Rec sup & indigena & cerám. & 2,5 & 5 & 7 & 5 & biplana & 1/4 de la pieza. Reutilización frag cerám. Cocción oxidante. Ambas superficies desgastadas por \\
\hline & & & & & & & & & erosión. La pasta contiene abundantes tiestos molicos de granulomet. pequeña de color negro. \\
\hline 10 & S48 W12 & indigena & cerám & 52 & 7 & 8 & 14 & biplana & $1 / 2$ de la pieza. Reutilizacion fragm ceramico. Parte sup. Eng pulido color ocre reverso alisado \\
\hline & & & & & & & & & alisado con restos pintura roja. Pasta reduct. con tiestos molidos. Orificio hecho desde la cara sup. \\
\hline 11 & Rec. sup & indigena & cerám & 3,7 & 4 & 7 & 6 & biplana & 1/4 de la pieza. Reutilización fragm cerám. Sup. ext pulida, interna alisada. Cocción reductora. \\
\hline 12 & Rec sup & indigena & céram & 2,7 & 5 & 5 & 3 & biplana & 1/4 de la pieza. Reutilización fragm cerám. Forma irregular. Color ocre en ambas caras. Cocción \\
\hline & & & & & & & & & reductora. Se observa orificio central \\
\hline 13 & Rec.sup & americ. & loza & 3,1 & 3 & 6 & 3 & biplana & 1/4 de la pieza. Reutiliz de frag. loza Panamá policromo. Motivos fitomorfos color celeste, \\
\hline & Cañadita & Panamá.Poli & & & & & & & línea amarilla sobre base blca. Sup inferior blancuzca.. Pasta roja. \\
\hline 14 & Rec sup & Talavera & mayólica & 2,9 & 5 & 6 & 3 & biplana & 1/2 de la pieza. Reutiliz de frag de mayólica Talavera. En la parte sup.lineas de color azul, figura \\
\hline & barranca & & & & & & & & fitomorfa. Parte inferior de color blanco. Pasta blanca. \\
\hline 15 & Rec. sup & Ichtukne & mayólica & 2,9 & 3,2 & 5 & 5 & biplana & 1/4 de la pieza. Reutiliz de frag.de plato de mayol Ichtuknee. Motivo lineal en óvalos de color \\
\hline & & & & & & & & & celeste/azul de diferentes grosores. Parte inf de color blco con dos pequeñas manchas celestes. \\
\hline
\end{tabular}

Tabla 2: En esta Tabla se realiza un estudio de su procedencia - cuadrícula, recolección superficial, medidas, peso y la descripción pormenorizada de cada uno de ellos- a fin de aportar y ampliar la base de datos que se posee hasta el momento, sobre este material tan específico.

\section{Conclusión}

Si bien es una acotada colección de artefactos, hasta el momento y en este sector de la provincia no se han reportado hallazgos sobre este tipo de materiales.

Creemos que la producción textil fue doméstica. El tipo de manufactura de los torteros, su peso, y el diámetro máximo, sostienen esta presunción.

Estos datos obtenidos nos alentaron a suponer que, por las características físicas de estos elementos, se pudieron haber hilado y tejido algodón procedente de las chacras santafesinas y correntinas y también haber utilizado fibras animales como la lana producida por el ganado ovino que se criaba en chacras y estancias de la región.

Como la actividad textil requiere tiempo para la preparación de los hilos, vinculamos esta práctica 
al ámbito femenino pues, siendo en sus comienzos una reducción y luego una encomienda, las tareas de los varones para esa época, estuvieron orientadas a la cría y cuidado del ganado bovino y mular y a la cosecha del algodón en escala mínima. Por lo tanto, inferimos que la producción textil -procesamiento, hilado y tejido- pudo haber estado a cargo de las mujeres, realizada en ámbitos domésticos y haber sido destinada a la confección y reparación de ropa personal de cada familia.

\section{Referencias bibliográficas}

ARTURI, M. J. (1984). El algodón. Mejoramiento genético y técnica de cultivo. Hemisferio Sur S.A.

CERVERA, M. N. (1982) Historia de la Ciudad y Provincia de Santa Fe. Contribución a la Historia de la República Argentina, 1573 - 1853 Tomo III: págs:385/386.

LOZANO, P. (1874) Historia de la conquista del Paraguay, Rio de La Plata y Tucumán.1697/1752. Tomo I. Casa Editora Imprenta Popular

MOLINA, R. A. (1948). Hernandarias: el hijo de la tierra. Editorial Lancestremere.

REVISTA DE LA BIBLIOTECA NACIONAL (1937) Tomo I (2), 386-387.

SCHAVELZON, D. (1998) Informe sobre las lozas de La Boca del Monje al Proyecto San Bartolomé de los Chaná. Secretaría de Ciencia y Técnica, Universidad Nacional de Rosario. MS

Recibido: 10-04-2020

Aceptado: 29-06-2020 